\title{
Associations of allergic sensitization and clinical phenotypes with innate immune response genes polymorphisms are modified by house dust mite allergen exposure
}

Marcin Kurowski, Barbara Majkowska-Wojciechowska, Aleksandra Wardzyńska, Marek L. Kowalski

Department of Immunology, Rheumatology and Allergy, Medical University of Lodz, Poland

Submitted: 2 February 2011

Accepted: 9 April 2011

Arch Med Sci 2011; 7, 6: 1029-1036

DOI: 10.5114/AOMS.2011.26616

Copyright $\odot 2011$ Termedia \& Banach

\section{Abstract}

Introduction: Polymorphisms within innate immunity genes are associated with allergic phenotypes but results are variable. These associations were not analyzed with respect to allergen exposure. We investigated associations of TLR and CD14 polymorphisms with allergy phenotypes in the context of house dust mite (HDM) exposure.

Material and methods: Children, aged $12-16$ years $(n=326)$, were recruited from downtown and rural locations and assessed by allergist. Skin prick tests, total and HDM-specific slgE measurements were done. HDM allergen concentrations in dust were measured. Genetic polymorphisms were identified using restriction fragment length polymorphism (RFLP).

Results: Allergic rhinitis, asthma and atopy were more prevalent in urban area. Although HDM allergen concentrations were higher in rural households, slgE were present more frequently in urban children. In the whole population no association was found between HDM exposure and sensitization. In children with CD14/-159CC, CD14/-159TT and TLR9/2848GA genotypes increased exposure to HDM was associated with reduced incidence of allergic rhinitis. Significant associations of increased HDM exposure with reduced incidence of atopy were found for the whole population and subjects with CD14/-159CC, CD14/-1359GT, TLR4/896AA and TLR9/2848GA genotypes. Among children with CD14/-159CC and CD14/-1359GG significant positive correlation between HDM allergen concentrations in household and sensitization to HDM was observed. In contrast, protective effect of high HDM allergen exposure against specific sensitization was seen in subjects with TLR4/896 AG.

Conclusions: Development of specific sensitization and allergy may be associated with innate immune response genes polymorphisms and is modified by allergen exposure.

Key words: allergy, CD14, toll-like receptors, house dust mite exposure, polymorphism.

\section{Introduction}

It is becoming evident that development of allergic sensitization and disease is a result of complex gene-by-environment interaction rather than an effect of single gene expression. These gene-environment interactions have often been interpreted in the context of assuming a link between improve-

\section{Corresponding author:}

Prof. Marek L. Kowalski MD, $\mathrm{PhD}$

Department of Immunology, Rheumatology and Allergy Medical University of Lodz E-mail: marek.kowalski@ csk.umed.lodz.pl 
ment of living conditions and gradual increase in allergic disease morbidity observed over the last decades [1]. Genes coding for CD14 (an LPS receptor) and toll-like receptors (TLR) belong to the most extensively studied in this context [2-5]. In the CD14 gene, the promoter variant C-159T was found to be associated with lower total serum IgE concentrations [6-8], higher concentrations of soluble CD14 [8, 9], and less severe asthma phenotype [10, 11]. Genetic variants C-159T, C-260T and C-1721T within CD14 have been reported as possibly interacting with environmental factors during development of allergy [12-15]. A CD14/-159 CC genotype was associated with increased specific bronchial hyperreactivity to Dermatophagoides pteronyssinus allergen and higher concentrations of house dust mite (HDM)-specific IgE [16]. Toll-like receptor type 4 (TLR4) is crucial for bacterial endotoxin recognition and its genetic variants were considered important in altering the responsiveness to endotoxin $[5,17]$. Despite the existence of data strongly suggesting the influence of the A896G polymorphism on interruption of TLR4 signalling [18], studies addressing possible associations between TLR4 variants and asthma have brought conflicting results [7, 19-21]. Another toll-like receptor, TLR9, has been shown to mediate maturation of dendritic cells (DC) and production of proinflammatory cytokines after exposure to unmethylated CpG-rich bacterial DNA. Activation of DC via TLR9 leads to improvement of their antigen-presenting capacities [22]. Moreover, interferon- $\alpha$ (IFN- $\alpha$ ) production and release by DC is TLR9 dependent. Interferon- $\alpha$ plays an important role in controlling the adaptive immunity through influencing IFN- $\gamma$ release from $T$ cells and immunoglobulin class switching in B cells. Therefore, failure in TLR9 activation may result in lack of skewing of the immune response towards Th1 profile and increase in IgE levels [23]. These hypotheses are further confirmed by lower TLR9 expression described in non-atopic children growing up in poor hygiene conditions [24]. One of the studies revealed increased probability of asthma among Americans of European descent carrying C allele at -1237 in TLR9 [25]. Novak et al. [26] suggested an association between C-1237T polymorphism and susceptibility to intrinsic variant of atopic eczema. However, other studies $[27,28]$ did not demonstrate any influence of TLR9 polymorphisms on the presence of atopy and asthma. Exposure to various environmental factors in early life influences susceptibility to development of allergic sensitization and disease [29-32]. Studies aimed specifically at investigation of the influence of endotoxin exposure on allergy development in the context of genetic influence [12] have shown clear evidence for the interdependence of endotoxin exposure, genotype and presence of atopy features. However, in spite of the critical role of allergen exposure for de- velopment of allergy and allergic sensitization association of these phenotypes with innate immune response genes variants are rarely analysed with respect to the allergen exposure.

The goal of our study was to assess associations of CD14 and TLR polymorphisms with phenotypes of atopic allergy in the context of allergen exposure.

\section{Material and methods}

\section{Study population}

The study group consisted of 326 children aged 12 to 16 years recruited from two different living environments in central Poland. The first group consisted of 168 children sampled from the population of children attending two schools located in a downtown area of Lodz, an industrial city of ca. 750,000 inhabitants in central Poland, whereas the second included 158 children attending two schools located in typically agricultural rural communities in central Poland located 50 to $100 \mathrm{~km}$ from the city of Lodz.

\section{Ethics}

The study was approved by the Bioethics Commission of the Medical University of Lodz. Children's parents or guardians gave informed consent for all proceedings required during the study.

\section{Clinical and laboratory evaluation}

The parents or guardians of children completed a questionnaire on general household characteristics, living conditions, environmental exposures, farming characteristics (in rural children), dietary habits, maternal history of pregnancy and pet ownership. Following the initial review of the questionnaire, the children were invited for assessment by a trained allergist including history, physical examination, skin prick testing and blood withdrawal for IgE assessment. Based on history, clinical examination and results of the skin prick test (SPT), the allergist proposed the final diagnosis with regard to allergic diseases.

Skin prick tests were carried out using the extracts of 15 allergens: D. pteronyssinus, D. farinae, cat, dog, rabbit, hamster, guinea-pig, rat, swine, birch, grass mix, mugwort, plantain, Alternaria tenuis and Cladosporium herbarum and positive and negative controls (Allergopharma, Reinbek bei Hamburg, Germany). A wheal diameter of $3 \mathrm{~mm}$ or more was considered positive. For the purpose of the current study, atopic sensitization was defined as the presence of positive SPT with at least one allergen.

Serum total IgE and specific IgE to Der $p 1$ were measured by the ImmunoCAP assay (Pharmacia Upjohn Diagnostics AB, Uppsala, Sweden) in accordance with the manufacturer's instructions. 


\section{Environmental exposure}

Dust samples were collected at children's houses through vacuum cleaning of $1 \mathrm{~m}^{2}$ of the carpet in the child's bedroom for $2 \mathrm{~min}$. If there was no carpet in the child's bedroom, a dust sample was collected from the armchair, sofa, or other upholstered piece of furniture. Dust samples were collected using a Kirby vacuum cleaner with Micron Magic MicroAllergen Reduction Filters (The Kirby Company, Cleveland, OH, USA). All dust samples were collected and subsequently processed by the same investigator. Concentrations of Der $p 1$ allergen in house dust samples were measured using ELISA kits for antigen quantitation (INDOOR Biotechnologies Inc., Charlottesville, VA, USA).

\section{Genotyping}

Genomic DNA was isolated from $5 \mathrm{ml}$ of peripheral blood collected into tubes containing sodium citrate as an anticoagulant. Genomic Maxi AX DNA isolation kits (A\&A Biotechnology, Gdynia, Poland) were used in accordance with the protocol provided by the manufacturer. Presence of polymorphisms was ascertained using the restriction fragment length polymorphism (RFLP) method. DNA fragments containing respective polymorphic loci were amplified using specific primers described previously $[6,11,28,33]$, as shown in Table I. Amplified products were subsequently digested with appropriate restriction endonuclease. All enzymes were purchased from Fermentas (Vilnius, Lithuania). One of the primers used in TLR4 A896G polymorphism determination was modified in order to create a recognition site for restriction enzyme (amplification-created recognition site [ACRS-]RFLP). The digested fragments were separated by electrophoresis in $2 \%$ agarose gel and visualised in UV light with ethidium bromide staining.

\section{Statistical analysis}

Statistical analyses were performed using Statistica 6.0 software (StatSoft Inc., Tulsa, OK, USA).
Differences regarding quantitative traits were analysed using nonparametric Mann-Whitney $U$ test. Hardy-Weinberg equilibrium was tested using the $\chi^{2}$ test. The $\chi^{2}$ test or Fisher's exact test was used for comparison of differences in genotype frequencies within the groups and for comparisons of frequency of allergic phenotypes depending on the level of mite allergen exposure. Spearman's rank order correlations were calculated when investigating correlations between household Der $p 1$ concentration and specific IgE concentration. Total and specific IgE concentrations were subject to 'by-genotype' analysis with regard to polymorphisms at CD14/-159, CD14/-1359, TLR4/896 and TLR9/2848. Kruskal-Wallis test was employed, with correction for multiple comparisons. $P_{\text {corr }}$ less than 0.05 was considered significant. During analyses involving serum concentration of specific Der $p 1$ IgE, only subjects with slgE level exceeding $0.35 \mathrm{kU} / \mathrm{l}$ (i.e., class 1 or higher) were included.

\section{Results}

\section{Clinical and immunological characteristics of urban and rural children}

A significantly higher percentage of children living in urban areas compared with those living in rural communities had doctor-diagnosed allergic rhinitis (39.8\% vs. $10.8 \%, p<0.05)$, asthma $(16.4 \%$ vs. $2.0 \%, p<0.05)$, positive SPTs to at least 1 allergen $(58.9 \%$ vs. $20.9 \%, p<0.0001)$ and positive SPT with house dust mite allergen $(34.75 \%$ vs. $15.18 \%$; $p<0.0001)$ - Figure 1. In the urban group, 68 children had Der $p 1$ specific IgE $(>0.35 \mathrm{kU} / \mathrm{l})$ in serum as compared to 22 children in the rural group (33.8\% vs. $10.8 \%$, respectively; $p<0.0001$ ). The mean concentration of Der $p 1$ specific IgE in urban children tended to be higher $(16.2 \pm 3.15 \mathrm{kU} / \mathrm{l}$ vs. $8.75 \pm 2.68 \mathrm{kU} / \mathrm{l}, p>0.05)$. No significant difference in the mean serum total IgE level was observed between urban and rural populations $(180.58 \pm 24.53$ vs. $150.84 \pm 22.88 \mathrm{kU} / \mathrm{l}$, respectively, $p>0.05$ ). Der $p 1$ concentration in dust samples collected

Table I. Primers and restriction enzymes used for determination of polymorphisms. Site of modification in one of the primers used during amplification of TLR4 fragment was put into frame

\begin{tabular}{|c|c|c|c|c|}
\hline Gene & Polymorphism & Primers & Enzyme & Ref. \\
\hline \multirow[t]{2}{*}{ CD14 } & C-159T & 5'-GTGCCAACAGATGAGGTTCAC-3' & Eco47I & Baldini et al. [6] \\
\hline & & 5'-GCCTCTGACAGTTTATGTAATC-3' & & \\
\hline \multirow[t]{2}{*}{ CD14 } & G-1359T & 5'-GTTGCAGTGAGCCAAGATCA-3' & BseGl & Bučková et al. [11] \\
\hline & & 5'-CCCTAGACCTCTGGGGAAAG-3' & & \\
\hline \multirow[t]{2}{*}{$T L R 4$} & A896G & 5'-GATTAGCATACTTAGACTACTACCTCCATG-3' & Ncol & Reismann et al. [33] \\
\hline & & 5'-GATCAACTTCTGAAAAAGCATTCCCAC-3' & & \\
\hline \multirow[t]{2}{*}{ TLR9 } & G2848A & 5'-AAGCTGGACCTCTACCACGA-3' & Ssil & Noguchi et al. [28] \\
\hline & & 5'-TTGGCTGTGGATGTTGTTGT-3' & & \\
\hline
\end{tabular}




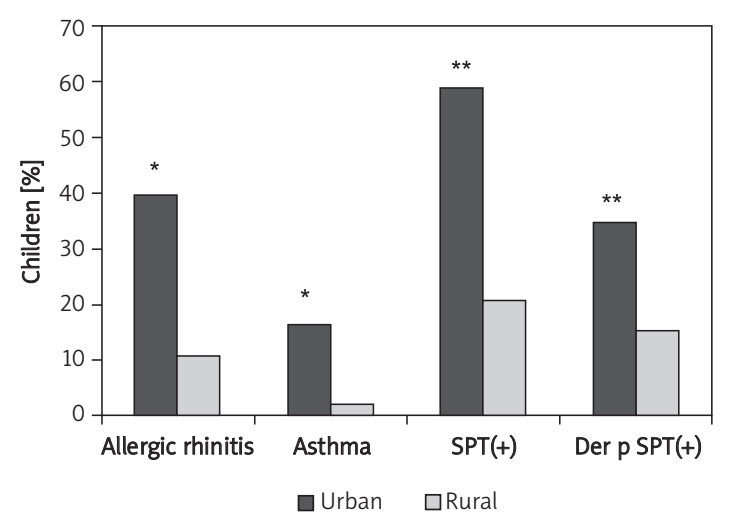

Figure 1. Frequency of doctor-diagnosed allergic rhinitis and asthma as well as positive SPT with at least one allergen and positive SPT with Dermatophagoides pteronyssinus in children from urban and rural communities

${ }^{*} p<0.05$ and ${ }^{* *} p<0.0001$ vs. rural group

from carpets in children's bedrooms were significantly higher in rural areas $(1.018 \pm 0.08 \mu \mathrm{g} / \mathrm{g}$ dust $)$ as compared to urban households (0.378 \pm 0.07 $\mu \mathrm{g} / \mathrm{g}$ dust, $p<0.0001)$.

\section{Associations of allergic phenotypes and sensitization with allergen exposure}

In the whole group, no association was found between exposure to dust mite allergen at home and presence of allergic rhinitis or bronchial asthma. However, when the population of children was stratified according to the intensity of exposure to HDM allergens into three groups (less than $0.5 \mu \mathrm{g} / \mathrm{g}$ dust [182 households]; 0.5 to $2.0 \mathrm{\mu g} / \mathrm{g}$ dust [82 households]; and more than $2.0 \mu \mathrm{g} / \mathrm{g}$ dust [34 households]), atopy was found to be more frequent in subjects exposed to the lowest concentrations of HDM allergens at home (78.9\%) compared to those exposed to medium and low concentrations (32.1\% and $37.0 \%$, respectively; $p=0.026, \chi^{2}$ test).

Genotype frequencies did not differ significantly among children with different allergic phenotypes or children from urban and rural living environments (data not shown). Analysis of genotypes in children with different allergic phenotypes showed a tendency to higher prevalence of asthma in carriers of GG genotype at TLR9/2848 (16.28 \%) as compared to carriers of GA and AA genotypes (8.96\% and $7.69 \%$, respectively), but these differences were not statistically significant (Table II). Children with TLR9/2848 GG genotype had significantly higher serum specific Der $p 1$ IgE levels as compared to GA and AA genotypes (42.18 \pm 13.86 vs. $10.66 \pm 3.89$ and $13.35 \pm 4.76 \mathrm{kU} / \mathrm{l}$, for $G G, G A$ and $A A$ genotype respectively; mean $\pm \mathrm{SEM} ; p=0.04$ ).

Table II. Distribution of frequency of allergic diseases and selected features of atopy according to genotypes ( $n=326)$

\begin{tabular}{|c|c|c|c|c|c|}
\hline $\begin{array}{l}\text { Gene, locus } \\
\text { and genotype }\end{array}$ & $\begin{array}{c}\text { Asthma } \\
{[\%]}\end{array}$ & $\begin{array}{c}\text { Allergic } \\
\text { rhinitis [\%] }\end{array}$ & $\begin{array}{c}\text { Atopic } \\
\text { dermatitis [\%] }\end{array}$ & $\begin{array}{c}\text { SPT positive } \\
{[\%]}\end{array}$ & $\begin{array}{c}\text { Total lgE } \\
>100 \mathrm{kU} / \mathrm{l}[\%]\end{array}$ \\
\hline \multicolumn{6}{|l|}{ CD14/-159 } \\
\hline $\mathrm{CC}$ & 8.11 & 23.42 & 0.00 & 30.63 & 36.04 \\
\hline $\mathrm{CT}$ & 11.04 & 26.62 & 2.60 & 42.86 & 33.77 \\
\hline $\mathrm{TT}$ & 7.91 & 23.74 & 1.44 & 46.04 & 32.79 \\
\hline$p$ value $\left(\chi^{2}\right.$ test) & $>0.05$ & $>0.05$ & $>0.05$ & $>0.05$ & $>0.05$ \\
\hline \multicolumn{6}{|l|}{ CD14/-1359 } \\
\hline $\mathrm{GG}$ & 9.89 & 26.92 & 1.65 & 40.11 & 29.55 \\
\hline GT & 9.17 & 22.02 & 0.00 & 35.78 & 29.41 \\
\hline $\mathrm{TT}$ & 7.96 & 23.89 & 2.65 & 46.02 & 22.22 \\
\hline$p$ value $\left(\chi^{2}\right.$ test) & $>0.05$ & $>0.05$ & $>0.05$ & $>0.05$ & $>0.05$ \\
\hline \multicolumn{6}{|l|}{$T L R 4 / 896$} \\
\hline AA & 9.79 & 24.48 & 1.75 & 36.71 & 33.57 \\
\hline $\mathrm{AG}$ & 7.32 & 26.83 & 0.00 & 51.22 & 41.46 \\
\hline$p$ value $\left(\chi^{2}\right.$ test) & $>0.05$ & $>0.05$ & $>0.05$ & $>0.05$ & $>0.05$ \\
\hline \multicolumn{6}{|l|}{$T L R 9 / 2848$} \\
\hline GG & 16.28 & 18.61 & 0.00 & 34.88 & 30.23 \\
\hline GA & 8.96 & 28.36 & 1.49 & 41.79 & 32.09 \\
\hline AA & 7.69 & 21.89 & 1.78 & 34.91 & 36.09 \\
\hline$p$ value ( $\chi^{2}$ test) & $>0.05$ & $>0.05$ & $>0.05$ & $>0.05$ & $>0.05$ \\
\hline
\end{tabular}




\section{Association of allergic phenotypes with genotypes in the context of allergen exposure}

In children with CD14/-159 CC genotype, atopy was significantly more frequent among those exposed to the lowest concentrations of HDM allergens at home as compared to children exposed to medium and high concentrations ( $43.9 \%$ vs. $22.7 \%$ vs. $25.0 \%$, respectively; $p=0.04, \chi^{2}$ test). A similar association was observed in CD14/-159 CC carriers with regard to presence of allergic rhinitis symptoms ( $30.4 \%$ vs. $8.3 \%$ vs. $18.2 \% ; p=0.02, \chi^{2}$ test). In children with CD14/-159 TT genotype, exposure to low HDM allergens concentration was also associated with higher frequency of allergic rhinitis ( $38.5 \%$ vs. $22.2 \%$ vs. $25.0 \%$, respectively), but this association was on the verge of statistical significance ( $p=0.048, \chi^{2}$ test).

Analysis of CD14/-1359 polymorphisms showed that atopy was encountered more frequently in GT heterozygotes exposed to house dust mite allergens at concentrations lower than $0.5 \mu \mathrm{g} / \mathrm{g}$ dust (50.0\% vs. $29.4 \%$ and $27.3 \%$ for $0.5-2.0$ and $>2.0 \mu \mathrm{g} / \mathrm{g}$ dust; $p=0.04, \chi^{2}$ test).

Among subjects with TLR9/2848 GA genotype, atopy and allergic rhinitis were more frequent in those exposed to the lowest HDM allergen concentrations compared to medium and high concentrations ( $54.5 \%$ vs. $25.8 \%$ vs. $40 \%$; $p=0.035$, $\chi^{2}$ test).

No other significant associations of genotype, allergen exposure and allergy symptoms were ascertained.

\section{Genotypes and sensitization to Der p 1 allergen in the context of Der $p 1$ exposure}

In the whole group, no significant correlation between household dust mite allergen concentration and level of specific IgE to Der $p 1$ was observed $(R=0.26, p=0.06)$. However, a signifi-

\section{A}

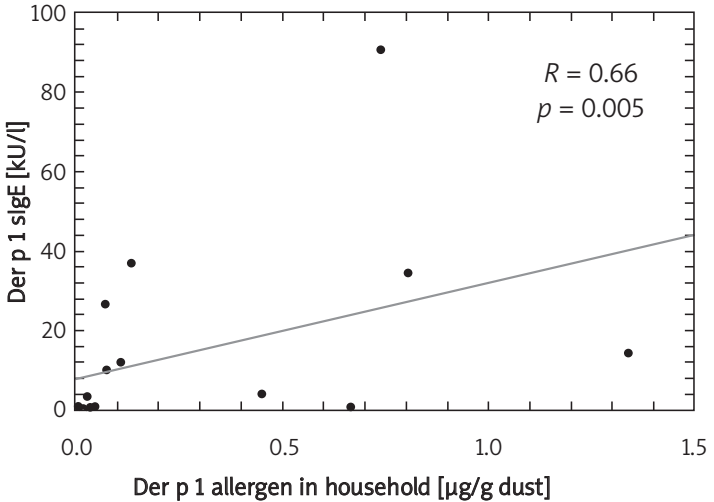

cant positive correlation between dust mite allergen concentrations in household and specific IgE to Der $p 1$ was noted in children with CD14/-159 CC genotype $(R=0.66 ; p=0.005)$ and in children with CD14/-1359 GG genotype $(R=0.57 ; p=0.003)-$ Figure 2. There were no such correlations in children with other genotypes.

The percentage of children sensitized to Der $\mathrm{p} 1 \mathrm{al}-$ lergen and stratified according to the level of Der $p 1$ exposure did not vary among carriers of different variants of CD14/159, CD14/1359 or TLR 9/2848 genes. Only the presence of TLR4/896 variant was found to affect the prevalence of sensitization depending on the different levels of Der $p 1$ allergen at home $(p=0.03)$ - Table III. Although a similar percentage of children with TLR/896 AA genotype, regardless of the level of exposure, was sensitized to Der $p 1$ antigen, among children with TLR/896 AG genotype the sensitization rate was inversely related to the level of exposure. Children with this genotype, exposed to the highest ( $>2 \mu \mathrm{g} / \mathrm{g}$ dust) concentrations of Der $\mathrm{p} 1$, had the lowest rate of sensitization (14.3\%), while children exposed to the lowest Der $p 1$ concentrations (< $0.5 \mu \mathrm{g} / \mathrm{g}$ dust) had the highest sensitization rate (64.3\%). Among children with medium exposure to Der p 1 ( 0.5 to $2.0 \mu \mathrm{g} / \mathrm{g}$ dust), an intermediate rate of sensitization was observed (33.3\%). Moreover, in the highest Der $\mathrm{p} 1$ exposure group, significantly more TLR4/896 AG carriers were sensitized to HDM compared to TLR4/896 AA carriers (64.3\% vs. $30.6 \%$, respectively; $p<0.02)$ - Figure 3 .

No differences in total IgE levels were observed between carriers of different genotypes at CD14/ -159, CD14/-1359, TLR4/896 and TLR9/2848 - data not shown.

\section{Discussion}

In the present study we demonstrated that, although development of allergic phenotypes and

\section{B}

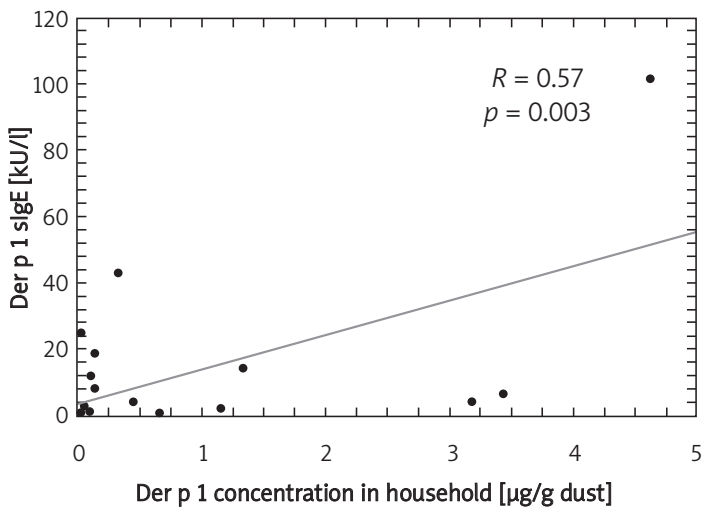

Figure 2. Correlations between house dust mite allergen concentrations in households and specific Der $p 1$ IgE levels in serum in children with CD14/-159 CC (A) and CD14/-1359 GG (B) genotypes. Spearman's correlation coefficients were calculated 
Table III. Percentage of children with different genotypes having positive SPTs with house dust mites in relation to the intensity of Der $p 1$ allergen exposure

\begin{tabular}{|c|c|c|c|c|c|}
\hline \multirow[t]{2}{*}{ Genotype } & & \multicolumn{3}{|c|}{ House dust mite allergen Der $p 1$ concentration in household } & \multirow[t]{2}{*}{ Value of $p$} \\
\hline & & $<0.5 \mu \mathrm{g} / \mathrm{g}$ dust [\%] & $0.5-2.0 \mu \mathrm{g} / \mathrm{g}$ dust [\%] & $>2.0 \mu \mathrm{g} / \mathrm{g}$ dust $[\%]$ & \\
\hline \multirow[t]{3}{*}{ CD14/-159 } & $\mathrm{CC}$ & 31.1 & 17.4 & 30.0 & $>0.05$ \\
\hline & $\mathrm{CT}$ & 24.6 & 22.2 & 20.0 & $>0.05$ \\
\hline & $\mathrm{TT}$ & 46.2 & 11.8 & 28.6 & $>0.05$ \\
\hline \multirow[t]{3}{*}{ CD14/-1359 } & GG & 25.0 & 31.0 & 42.9 & $>0.05$ \\
\hline & GT & 25.5 & 26.9 & 11.1 & $>0.05$ \\
\hline & $\mathrm{TT}$ & 41.7 & 22.7 & 0 & $>0.05$ \\
\hline \multirow[t]{2}{*}{ TLR4/896 } & AA & 30.6 & 18.9 & 36.8 & $>0.05$ \\
\hline & $A G$ & 64.3 & 33.3 & 14.3 & 0.03 \\
\hline \multirow[t]{3}{*}{ TLR9/2848 } & GG & 31.3 & 16.7 & 0 & $>0.05$ \\
\hline & GA & 34.5 & 12.1 & 41.7 & $>0.05$ \\
\hline & $A A$ & 44.4 & 25.0 & 28.6 & $>0.05$ \\
\hline
\end{tabular}

sensitization may be associated with innate immunity gene polymorphisms, these associations are modified by exposure to house dust mite allergens. In CD14/-159 CC homozygotes we observed a significant positive correlation between Der $\mathrm{p} 1$ specific lgE levels and household Der $p 1$ allergen concentration. However, subjects having CD14/-159 CC genotype and exposed to higher levels of HDM allergens at home were significantly less likely to be sensitized to one or more allergens and to develop allergic rhinitis symptoms. The association of CD14 gene polymorphism with presence of allergic disease was investigated in the context of environmental exposure to endotoxin and mite allergens by Simpson et al. [12]. In subjects with CD14/159 CC genotype those authors described an inverse relation between intensity of environmental endotoxin exposure and allergic sensitization. In the context of dust mite exposure, Simpson et

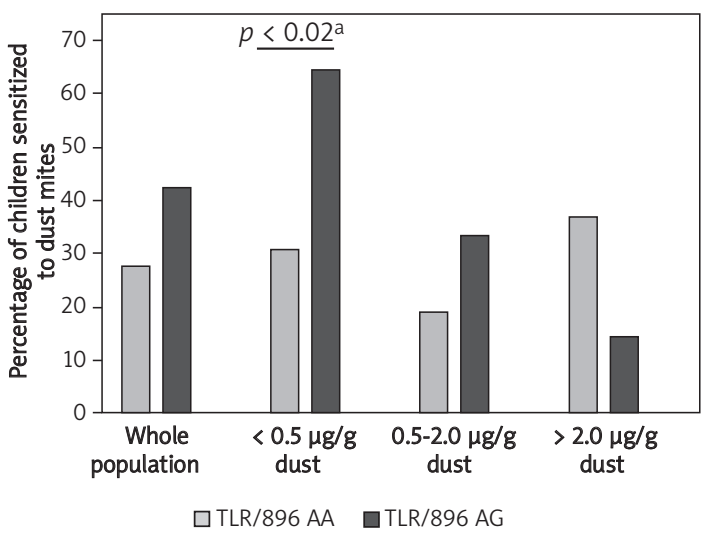

Figure 3. Frequency of sensitization to dust mites among carriers of TLR4/896 genotypes exposed to different concentrations of dust mite allergens at home

aFisher's exact test al. [12] observed (also in subjects with CD14/-159 CC genotype) an increased risk of mite sensitization upon increased mite allergen exposure and decreased endotoxin exposure.

In different populations, CC genotype at CD14/ -159 has been or has not been associated with atopic predisposition $[10,11]$. One reason for such discrepancies may be the fact that genotype frequencies may substantially vary depending on the ethnic composition of the studied population [34]. Secondly, most studies did not address the issue of the intensity of allergen or endotoxin exposure in the living environment. Our results, similarly to those published by Simpson [12], prove that the postulated original role of CD14/-159 genotypes in allergy and atopy development may be modified by environmental factors.

We have demonstrated that in CD14/-1359 GG homozygotes, household dust mite allergen exposure is positively correlated with the level of serum specific IgE to Der $p$ 1. Studies performed so far have shown that $G$ allele at CD14/-1359 was associated with lower total IgE levels and lower frequency of positive SPTs [11,35]. To the best of the authors' knowledge, however, to date no study has addressed the issue of the role of CD14/-1359 genetic variants in the development of allergic sensitization considering the intensity of specific allergen exposure.

The most striking effect of gene-environment interaction was observed when TLR4/896 polymorphism was analysed. Although among children with TLR4/896 AA genotype Der $p 1$ allergen concentration at home did not affect prevalence of sensitization to this allergen, in children with TLR/896AG genotype low exposure to Der $p 1$ was associated with a significantly higher sensitization rate. Thus, the presence of TLR4/896 AG polymor- 
phism seems to confer protection against allergic sensitization to dust mites in subjects exposed to high levels of Der $p 1$ allergen in the living environment. Other studies have reported increased risk of atopic asthma in subjects with this polymorphism [19] or failed to demonstrate any association between asthmatic phenotypes and TLR4 genotypes [20]. However, these studies did not take into account the intensity of allergen exposure.

We did not find any association of $G \rightarrow A$ TLR9/2848 polymorphism with the presence of allergic disease or features of atopy. Similarly to CD14/-159 CC carriers, subjects with GA TLR9/2848 genotype had a lower frequency of allergic rhinitis and a lower frequency of positive SPTs. Due to scarce data concerning this polymorphism and the relatively small number of examined subjects, we cannot provide any conclusive interpretation of this finding. Lazarus et al. [25] suggested increased risk for asthma in Americans of European descent carrying the $C$ allele at -1237 in the TLR9 gene. According to Novak et al. [26], presence of C $\rightarrow$ T TLR9/ -1237 polymorphism may predispose to atopic eczema. Other studies, similarly to ours, did not confirm associations of any TLR9 polymorphism with susceptibility to allergy [27, 28].

In conclusion, our data show that susceptibility to allergy and atopy may be associated with variants in genes coding for innate immunity elements and may be further modified by environmental allergen exposure. Therefore, intensity of allergen exposure should be taken into consideration when the influence of genetic variants on predisposition to allergy is studied.

\section{Acknowledgments}

This study was supported by the Medical University of Lodz, grant no. 502-11-446.

\section{References}

1. Strachan D. Hay fever, hygiene, and household size. $\mathrm{Br}$ Med J 1989; 299: 1259-60.

2. Eder W, Klimecki W, Yu L, et al. Toll-like receptor 2 as a major gene for asthma in children of European farmers. J Allergy Clin Immunol 2004; 113: 482-8.

3. Genuneit J, Cantelmo J, Weinmayr G, et al. A multi-centre study of candidate genes for wheeze and allergy: the International Study of Asthma and Allergies in Childhood Phase 2. Clin Exp Allergy 2009; 39: 1875-88.

4. Reijmerink N, Bottema R, Kerkhof M, et al. TLR-related pathway analysis: novel gene-gene interactions in the development of asthma and atopy. Allergy 2010; 65: 199-207.

5. Simpson A, Martinez FD. The role of lipopolysaccharide in the development of atopy in humans. Clin Exp Allergy 2010; 40: 209-23.

6. Baldini M, Lohman I, Halonen M, Erickson R, Holt P, Martinez F. A Polymorphism* in the $5^{\prime}$ flanking region of the CD14 gene is associated with circulating soluble CD14 lev- els and with total serum immunoglobulin E. Am J Respir Cell Mol Biol 1999; 20: 976-83.

7. Sackesen C, Karaaslan C, Keskin O, et al. The effect of polymorphisms at the CD14 promoter and the TLR4 gene on asthma phenotypes in Turkish children with asthma. Allergy 2005; 60: 1485-92.

8. Leung TF, Tang NLS, Sung YM, et al. The C-159T polymorphism in the CD14 promoter is associated with serum total IgE concentration in atopic Chinese children. Pediatr Allergy Immunol 2003; 14: 255-60.

9. Kabesch M, Hasemann K, Schickinger V, et al. A promoter polymorphism in the CD14 gene is associated with elevated levels of soluble CD14 but not with IgE or atopic diseases. Allergy 2004; 59: 520-5.

10. Koppelman GH, Reijmerink NE, Colin Stine O, et al. Association of a promoter polymorphism of the CD14 gene and atopy. Am J Respir Crit Care Med 2001; 163: 965-9.

11. Bučková D, Hollá LI, Schüller M, Znojil V, Vácha J. Two CD14 promoter polymorphisms and atopic phenotypes in Czech patients with IgE-mediated allergy. Allergy 2003; 58: 1023-6.

12. Simpson A, John SL, Jury F, et al. Endotoxin exposure, CD14, and allergic disease: an interaction between genes and the environment. Am J Respir Crit Care Med 2006; 174: 386-92.

13. Leynaert B, Guilloud-Bataille M, Soussan D, et al. Association between farm exposure and atopy, according to the CD14 C-159T polymorphism. J Allergy Clin Immunol 2006; 118: 658-65.

14. Bieli C, Eder W, Frei R, et al. A polymorphism in CD14 modifies the effect of farm milk consumption on allergic diseases and CD14 gene expression. J Allergy Clin Immunol 2007; 120: 1308-15.

15. Eder W, Klimecki W, Yu L, et al. Opposite effects of CD14/ -260 on serum IgE levels in children raised in different environments. J Allergy Clin Immunol 2005; 116: 601-7.

16. Kowal K, Bodzenta-Łukaszyk A, Pampuch A, et al. Analysis of -675 4G/5G SERPINE1 and C-159T CD14 Polymorphisms in House Dust Mite-Allergic Asthma Patients. J Invest Allergol Clin Immunol 2008; 18: 284-92.

17. Dong L, Li H, Wang S, Li Y. Different doses of lipopolysaccharides regulate the lung inflammation of asthmatic mice via TLR4 pathway in alveolar macrophages. J Asthma 2009; 46: 229-33.

18. Arbour NC, Lorenz E, Schutte BC, et al. TLR4 mutations are associated with endotoxin hyporesponsiveness in humans. Nat Genet 2000; 25: 187-91.

19. Fageras Bottcher M, Hmani-Aifa M, Lindstrom A, et al. A TLR4 polymorphism is associated with asthma and reduced lipopolysaccharide-induced interleukin-12(p70) responses in Swedish children. J Allergy Clin Immunol 2004; 114: 561-7.

20. Raby BA, Klimecki WT, Laprise C, et al. Polymorphisms in Toll-like receptor 4 are not associated with asthma or atopy-related phenotypes. Am J Respir Crit Care Med 2002; 166: 1449-56.

21. Yang IA, Barton SJ, Rorke S, et al. Toll-like receptor 4 polymorphism and severity of atopy in asthmatics. Genes Immun 2004; 5: 41-5.

22. Krieg A. CpG motifs in bacterial DNA and their immune effects. Annu Rev Immunol 2002; 20: 709-60.

23. Heeg K, Zimmermann S. CpG DNA as a Th1 trigger. Int Arch Allergy Immunol 2000; 121: 87-97.

24. Majak P, Brzozowska A, Bobrowska-Korzeniowska M, Stelmach I. Early exposure to unhygienic conditions and Infections is associated with expression of different Toll-like receptors. J Investig Allergol Clin Immunol 2009; 19: 260-5. 
25. Lazarus R, Klimecki WT, Raby BA, et al. Single-nucleotide polymorphisms in the Toll-like receptor 9 gene (TLR9): frequencies, pairwise linkage disequilibrium, and haplotypes in three U.S. ethnic groups and exploratory case-control disease association studies. Genomics 2003; 81: 85-91.

26. Novak N, Yu CF, Bussmann C, et al. Putative association of a TLR9 promoter polymorphism with atopic eczema. Allergy 2007; 62: 766-72.

27. Berghofer B, Frommer T, Konig IR, et al. Common human Toll-like receptor 9 polymorphisms and haplotypes: association with atopy and functional relevance. Clin Exp Allergy 2005; 35: 1147-54.

28. Noguchi E, Nishimura F, Fukai H, et al. An association study of asthma and total serum immunoglobin E levels for Toll-like receptor polymorphisms in a Japanese population. Clin Exp Allergy 2004; 34: 177-83.

29. Chang T, Pang A. Cumulative environmental changes, skewed antigen exposure, and the increase of allergy. Adv Immunol 2008; 98: 39-83.

30. Chan-Yeung M, Hegele R, Dimich-Ward H, et al. Early environmental determinants of asthma risk in a high-risk birth cohort. Pediatr Allergy Immunol 2008; 19: 482-9.

31. Marks GB. Environmental factors and gene-environment interactions in the aetiology of asthma. Clin Exp Pharmacol Physiol 2006; 33: 285-9.

32. Xepapadaki P, Manios Y, Liarigkovinos T, et al. Association of passive exposure of pregnant women to environmental tobacco smoke with asthma symptoms in children. Pediatr Allergy Immunol 2009; 20: 423-9.

33. Reismann P, Lichy C, Rudofsky G, et al. Lack of association between polymorphisms of the toll-like receptor 4 gene and cerebral ischemia. J Neurol 2004; 251: 853-8.

34. Zhang G, Goldblatt J, LeSouëf P. Does the relationship between IgE and the CD14 gene depend on ethnicity? Allergy 2008; 63: 1411-7.

35. Vercelli D, Baldini M, Stern D, Lohman I, Halonen M, Martinez FD. CD14: a bridge between innate immunity and adaptive IgE responses. J Endotoxin Res 2001; 7: 45-8. 